\title{
Assassinos seriais e os efeitos da sideração no psiquismo e no laço social*1
}

\author{
Klaylian Marcela Santos Lima Monteiro*2
}

Os processos que caracterizam a constituição da subjetividade dos assassinos seriais relacionam-se ao papel que neles têm o superego arcaico. Ao analisarmos as interfaces destes tipos de configurações psíquicas com os laços sociais, nos deparamos com as figuras dos assassinos seriais tratados como icones da cultura pós-moderna, uma vez que são idealizados em filmes, livros e séries de TV, além de serem cultuados por muitos por sua capacidade de encanto, inteligência e engodo, movimentos que sideram e compactuam com os laços sociais perversos observados na contemporaneidade.

Palavras-chave: Assassinos seriais, laço social, sideração, superego arcaico

*1 Trabalho apresentado no Colóquio Internacional sobre Metapsicologia da Perversão. Usos Sociais da Perversão, realizado em Recife (PE) nos dias 26, 27 e 28 de agosto de 2013.

${ }^{* 2}$ Faculdade Pernambucana de Saúde - FPS (Recife, PE, Br). 
Este artigo é o produto resumido de uma tese de doutorado, que se propõe, sob um enfoque psicanalítico, a trabalhar os principais processos que caracterizam a constituição da subjetividade dos assassinos seriais, relacionando-os ao papel que neles tem o superego arcaico.

Os assassinos seriais são indivíduos que cometem homicídios que guardam entre si profundas semelhanças quanto ao modus operandi. Por modus operandi, podemos compreender, segundo Douglas \& Olshaker (2002), técnicas que o criminoso emprega para cometer o crime. Nestes casos, observa-se uma relação entre as vítimas, possuidoras de um mesmo perfil e controle de todos os detalhes da situação criminosa, desde a preparação do crime até sua execução e ocultação das provas. Nos casos de homicídios em série, não se observam relações anteriores entre a vítima e o agressor, sendo a vítima tratada de forma humilhante e posta numa posição inferior perante o criminoso, sem condições de defesa e possuindo um valor simbólico para o homicida, valor este relacionado à motivação — interna — do crime.

As vivências internas dos homicidas em série baseiam-se em fantasias sexuais e sádicas e na necessidade imperiosa de satisfação de impulsos a elas relacionadas. Este terreno, configurado pelas leis do inconsciente, fatalmente promove o enaltecimento do ego em seu aspecto narcísico, indo até a "coisificação" do outro. A existência do homicida em série, dependerá da dominação e morte do outro.

Para Olivier Blanc (apud Bonfim, 2004), não se pode dissociar os assassinos em série da mídia. Os casos de assassinatos em série, ganham notoriedade em todos os veículos 
midiáticos ao redor do mundo. Em nossa região, o recente caso dos denominados Canibais de Garanhuns ganhou destaque internacional. Um homem e duas mulheres percorriam, como nômades, o Estado de Pernambuco, assassinaram várias mulheres e praticaram o canibalismo com seus corpos. A filha de uma das vítimas, de apenas cinco anos, foi feita refém do grupo durante muitos meses, tendo sido submetida à prática do canibalismo. Suas fantasias homicidas foram encenadas em um livro e um filme, por eles produzidos. Na prisão, não aceitam se alimentar adequadamente, pois ainda desejam carne humana, em breve irão a júri popular, após ter sido atestado que podem ser plenamente responsabilizados criminalmente por seus atos.

Neste sentido, nos aprofundamos no estudo da forma sádica e destrutiva do funcionamento psíquico destes indivíduos, em que o imperativo categórico do gozo se destaca numa configuração psíquica que, repetidamente, atua no meio externo por meio da concretização de fantasias arcaicas de destruição do objeto. Esta configuração de psiquismo, em nossa opinião, encontra-se ancorada no funcionamento sádico do superego arcaico, conceito apresentado na obra de Melanie Klein (1926).

Consideramos, ainda, que as fantasias e o exercício do narcisismo destrutivo, bem como os elementos da sideração - conceito desenvolvido no decorrer de nossa pesquisa, e que se traduz pela capacidade dos assassinos em série de hipnotizar, encantar e seduzir as vítimas — de um ponto de vista psíquico —, são partes muito importantes de seu modus operandi, não apenas no processo de "sedução" da vítima, mas sobretudo nos passos que se seguem, vale dizer, a tortura e assassinato, em que as fantasias de destruição são atuadas e efetivamente postas em prática (Monteiro, 2012).

Segundo o Dicionário Aurélio (2012), o termo sideração significa a capacidade de "aniquilar, atonizar, atordoar, aturdir, estarrecer, fulminar, paralisar". A atitude de sideração impossibilita que qualquer ação seja tomada e, sobretudo, desperta, no outro, o sentimento de horror, que o paralisa e o deixa vulnerável até a aniquilação.

Ao desenvolver este conceito, entendemos que a sideração se relaciona à questão da excisão das partes más do self e atinge o outro de modo a paralisar as partes sadias de seu psiquismo. A sideração provoca efeitos tanto na vítima direta dos atos dos homicidas seriais como no espectador - vítima indireta - configurando a incapacidade de existir, de pensar, de ser e, assim, de lutar por sua sobrevivência física e/ou psíquica. Descobrimos que este é o mecanismo que, efetivamente, aniquila.

Os efeitos da sideração no psiquismo são nefastos não apenas para as vítimas, que sofrem o aniquilamento, mas sobretudo para aquele que sidera, que igualmente fica sem saída, pois também se paralisa, uma vez que, ao se refletir nas águas de seu próprio espelho narcisista nele se afunda e, sem respirar, sucumbe à força 
destruidora do movimento pulsional. Após a trajetória da elaboração dos efeitos da sideração, agora entendemos melhor por que os assassinos seriais não sentem remorso ou culpa. Eles se ressentem do impedimento de não poder simbolizar o que é sentido, o que obviamente não justifica seus atos, apenas os motiva.

Analisando as interfaces destes tipos de configurações psíquicas com os laços sociais, nos deparamos com as figuras dos assassinos seriais tratados como verdadeiros ícones da cultura pós-moderna, uma vez que são idealizados em filmes, livros e séries de T.V, além de serem cultuados por muitos por sua capacidade de encanto, inteligência e engodo. Esses movimentos sideram o espectador da cena perversa e compactuam com os laços sociais, também perversos, observados na contemporaneidade.

\section{Laços sociais perversos, superego arcaico e sideração: indagações nos campos da clínica e da sociedade}

Entrevistamos alguns assassinos em série; nesta experiência, encontramos histórias distintas e configurações de personalidade diversas, porém um mesmo fenômeno - os assassinatos em série. São histórias de vida repletas de situações de abandono, desamparo, maus-tratos, violências física e sexual. No entanto, uma semelhança se impôs: a permanência na posição esquizoparanoide e com ela traços de uma sexualidade pré-genital, fantasias de caráter sádico, angústias insuportáveis, processos de cisão constantes e os efeitos da sideração sobre suas vítimas e sobre si mesmos.

As fantasias arcaicas são muito marcantes, de tom sádico-oral, envolvendo práticas de humilhação, tortura, vampirismo, esquartejamento e canibalismo. Sugando o sangue de suas vítimas e, assim, seus conteúdos bons, o assassino serial que nomeamos de Vlad, podia se sentir jovem e alimentado. Já no caso de outro assassino serial, por nós denominado Jeckyll, as fantasias apresentavam um caráter arcaico, marcadamente voltadas ao controle muscular e posterior escavação e despedaçamento dos corpos. A forma como é relatado o uso sádico do pênis dá o tom, em ambos os casos, da mesma necessidade de controle e dano ao objeto.

A configuração dos homicídios, com uma modalidade muito específica em cada caso, relacionada às suas tramas vivenciais, através do ciclo infindável da compulsão à repetição, nos deixa ver que estes indivíduos reproduziram seus próprios traumas na cena externa. Assassinaram - reiteradas vezes - o objeto dominador, como uma forma de apaziguar o padecimento gerado pelas pressões internas.

As vítimas-objeto, como as denominamos, pela modalidade como são fantasiadas enquanto reedições dos objetos primários, foram, em ambos os casos, 
sacrificadas. Com esta finalidade, foram submetidas aos danosos efeitos da sideração, na qual se processou o domínio necessário à execução e ao aniquilamento do perseguidor depois de fazê-lo sofrer. O mecanismo da repetição, apresentado pelos assassinos em série, corresponde àquilo que Freud (1914) denominou de atualizações, ou seja, a revivência de experiências passadas na realidade atual. Neste contexto, mais do que revivência, preferimos falar de atuação.

Pode-se perceber a incapacidade do ego do assassino serial em seguir adiante, porque os medos persecutórios o prendem a este ciclo infindável da compulsão à repetição, vivenciada por suas vítimas e por todos aqueles que se debruçam sobre suas histórias. Esta situação contamina seus psiquismos de tal modo que os tornam incapazes de amar, de desenvolver a confiança no objeto. O objeto bom e inteiro não parece poder, em seus casos, se estabelecer. Apenas um objeto parcial surge, por isso todo o quadro de desintegração egoica se apresenta. Faz-me pensar num caleidoscópio que produz a repetição de imagens. Neste caso, não se trataria de um mesmo objeto inteiro, mas de um objeto partido. Cada parte, o pedaço de um mesmo objeto. Por mais que se gire o caleidoscópio, ele nunca faz desaparecer as múltiplas imagens. No caso de ambos os assassinos em série, por mais que se gire este caleidoscópio, ele nunca fará a imagem integrar-se ao objeto.

Importante ressaltar é a questão da fixação da sexualidade em etapas pré-genitais - o que confere ao superego arcaico suas características sádicas. Nesta etapa, poderosas cotas de angústia invadem o self e o desintegram pelos intermitentes processos de cisão sofridos, conforme descrito por Klein (1958). Tudo isso reforça os efeitos da sideração sobre as vítimas dos homicidas em série. Ódio, voracidade e destrutividade são características das etapas pré-genitais e, portanto, das relações objetais parciais. Assim são as relações estabelecidas pelos assassinos seriais. A infindável tarefa de expulsar o sadismo para o meio externo se torna não apenas um mecanismo de defesa radical, mas paralisa os processos de simbolização responsáveis pela possibilidade de ascensão à posição depressiva (Klein, 1935). Estes psiquismos permanecem enredados nas teias da identificação projetiva e nelas prendem as vítimas, como representantes dos objetos. Nestas mesmas teias, o laço social perverso enreda e é enredado, transformando o fenômeno da violência, morte e subjugação do outro, num espetáculo a ser encenado, não apenas pelo homicida em série, mas por cada um de nós que nos debruçamos sobre as imagens, filmes e livros a respeito do tema, em que uma espécie de inversão de papéis ocorre e os homicidas em série ocupam o papel de protagonistas. A sociedade do espetáculo apenas está atenta à sua própria capacidade de siderar o espectador.

Assim, as relações com a realidade, tanto interna como externa, se tornam superficiais, distantes e sem espontaneidade, pelas graves perturbações do próprio self, ou, como tão bem descreveu Klein (1946), o sentimento do self. A inexistência de fronteiras entre o self e as imagos objetais amplia as características narcísicas 


\section{ARTIGOS}

destas configurações de subjetividade e motivam as passagens ao ato para o campo, inclusive do social. Na projeção de tais impulsos para o interior do corpo das vítimas, as fantasias de esvaziamento, despedaçamento, envenenamento ou de incorporação se processaram e ganharam espaço até mesmo midiático, resguardando o lugar de destaque que a personalidade narcísica imprime aos assassinos seriais e ampliando seu poder de sideração, tal qual um movimento de retroalimentação.

Dá-se, por sua vez, o aprisionamento das partes boas do self, assim as qualidades do objeto tendem a desaparecer, o self libidinal se perde e as fantasias de destruição e aniquilamento ganham cada vez mais força no psiquismo e na própria realidade externa, ressaltada, por sua vez, pelas vivências traumáticas. A impossibilidade de simbolizar estes aportes pulsionais finda por gerar o fenômeno dos homicídios em série, destacando um superego arcaico, cruel e tirânico. Nestes casos, há uma prevalência de objetos maus em que os estados de perseguição se sobressaem e o self mau se separa do self bom, diante da cisão egoica. Neste sentido, a própria relação objetal é cindida e como tal se impõe de modo narcísico. Realidade e fantasia são amalgamados num único espaço, espaço este em que a simbolização não cabe. Um narcisismo onipotente, maligno e destruidor ocupa todo este lugar, ora vazio pela impossibilidade de representação. As partes más do self exercem um domínio onisciente, em que tudo se torna possível.

A experiência do pensar sobre estas entrevistas nos levou a atingir um outro ponto de indagação. Por que Vlad apresentou todo um modus operandi organizado no decorrer do tempo das ações criminosas praticadas e Jeckyll, um modus operandi desorganizado? Explicamos a indagação.

$\mathrm{Na}$ perspectiva da psicologia criminal, assassinos seriais desorganizados, em geral, tratam-se de indivíduos psicóticos, são descritos como mais impulsivos no momento do crime e, por este prisma, não conseguiriam manter um padrão organizado quanto ao seu modus operandi. As cenas dos crimes são repletas de provas incriminatórias de suas ações, os locais são escolhidos ao acaso, o perfil das vítimas, inconsistente.

Assim, a psicologia criminal tipifica os assassinos seriais em organizados e desorganizados, exatamente pelas configurações das práticas delituosas de captura, planejamento, homicídio, ocultação dos corpos e provas incriminatórias, como armas dos crimes e souvenirs.

Os organizados apresentariam transtornos de personalidade antissocial psicopatia (ou como queiramos denominar, perversos), são percebidos como indivíduos que agem de forma mais articulada e premeditada, por isso, seu modus operandi apresenta-se organizado, com escolha do local, perfil de vítimas e cautela estremada na ocultação de provas incriminatórias.

Observamos, ao menos nos casos estudados na tese, que esta situação se põe de modo inverso, pois Vlad, nestes termos, apresentou-se como um assassino serial 
R E V I $\quad$ S $T$ A

LATINOAMERICANA

DE PSICOPATOLOGIA

F U N D A E N T A L

organizado, apesar de seu quadro psicótico, conseguindo ocultar as provas de seus crimes por longos meses, chegando a cometer 13 homicídios.

\section{Questionamentos finais... enquanto há esperança}

Por isso, destinamos ao leitor alguns questionamentos: em casos tão comprometidos como estes, tipificar ou classificar não está muito distante de poder apreender o que realmente se passa com o psiquismo e com a história individual de cada caso em questão? Compreender este fenômeno apenas pelo viés estrutural não seria cair no risco do reducionismo? Como lidar com um fenômeno tão complexo que atua diretamente nos laços sociais, sem fazer questionamentos? No entanto, do que valeria este estudo se ele não pudesse nos fazer pensar em algumas contribuições para a clínica e para a sociedade? Que tipo de pensamentos ele poderia nos suscitar? Algumas esperanças? Sempre é possível uma esperança.

Somos expostos, cotidianamente, a uma infinidade de casos de crianças e adolescentes que atiram em seus colegas na escola, em seus professores; que matam seus pais; ou jovens de classes sociais abastadas que põem fogo em pessoas em situação de risco nas ruas. E assim, os laços sociais perversos da contemporaneidade cultuam a violência e o bizarro. É preciso ampliar este espaço de discussão social. Qual seria a implicação das configurações sociais neste fenômeno? Para tanto, não seria preciso um novo olhar mais cuidadoso sobre o fenômeno para que novas indagações possam surgir? Há uma gama muito mais ampla e complexa de discussão sobre o fenômeno a ser desvelada.

O movimento aniquilatório da sideração, quando voltamos a atenção para o campo social, nos faz deparar com uma sociedade, da qual todos e cada um de nós faz parte, que prima pela ética da eficácia, da satisfação plena dos desejos que, narcisicamente, são alimentados a despeito do desejo e sofrimento alheio. Os ideais se tornaram de tal modo presentificados, que a mídia exerce o papel de propiciar a exaltação deste ideal narcísico, e sobretudo da montagem perversa na qual nos encaixamos para dar conta das demandas sociais. Somos cotidianamente siderados pelo poder do consumismo, do corpo perfeito, das drogas alucinógenas, da banalização do mal, da violência. Somos hipnotizados por uma realidade virtual que nos faz sentir menos humanos. Assim, como realidades virtuais perfeitas, somos convocados a assumir posturas cada vez menos voltadas ao outro e essencialmente menos humanizadas.

A trama sintomatológica, nesses casos, parece transcender quaisquer outros quadros de patologias narcísicas e/ou ligadas ao campo da agressividade. O caráter excessivo dos métodos sádicos, comparado aos atos perversos, apresentados pelos 


\section{ARTIGOS}

assassinos seriais e seu modus operandi, nos leva, neste momento, a pensar que se trata de um processo psíquico com características específicas, em especial pelas relações que já salientamos com os laços sociais.

Desde há algum tempo, a experiência clínica tem nos levado a esta necessidade de aprofundamento das questões relacionadas ao campo dos comportamentos homicidas - principalmente visando, quiçá, atuação precoce, nos casos de crianças que apresentam tendências antissociais (Winnicott, 1985). Ouvi, de alguns pacientes, relatos dos mais impressionantes sobre assassinatos praticados com absoluta distorção afetiva e de uma mãe, em específico, preocupações com os atos de destruição e agressividade praticados por seu filho, de apenas nove anos de idade. Não há a pretensão de prevenir atos antissociais, porém há a preocupação de que o fenômeno da violência seja desnudado e exposto em suas faces mais dolorosas à sociedade.

Caro leitor, somente a partir do discurso dos assassinos seriais, as questões deste escrito poderiam ser elaboradas, no sentido de que é na narrativa de suas experiências, e especialmente na suspensão dessas questões por nossa parte, seria possibilitada a abertura de um espaço no qual uma escuta flutuante estivesse destinada à tentativa de compreensão deste fenômeno, que está inscrito no social.

Estudar a dimensão dos processos psíquicos propriamente ditos, de organizações de personalidade peculiares como estas, é tarefa árdua, mas também recompensadora, especialmente quando é exatamente pela intersecção dos campos do saber que se formam novas visões.

Entre Vlad e Jeckyll, muitas semelhanças e diferenças, dois homens com histórias tão distintas, duas configurações de personalidade diversas, um mesmo fenômeno. Duas histórias de vida repletas de situações de abandono, desamparo, maus-tratos, violências física, sexual. Na configuração psíquica, dois caminhos díspares se processaram: com Vlad, de uma psicose se estabeleceu; com Jeckyll, um quadro perverso. Uma semelhança se interpõe: a permanência na posição esquizoparanoide e com ela traços de uma sexualidade pré-genital, fantasias de caráter sádico, ansiedades insuportáveis, processos de cisão constantes e os efeitos da sideração sobre suas vítimas. Entre Vlad e Jeckyll percebemos esta incapacidade do ego de seguir adiante, os medos persecutórios os prendem a este ciclo repetitivo descrito por tantos autores, vivenciado por suas vítimas e mesmo por mim, no contexto da sideração, e que por fim contamina seus psiquismos de tal modo que os tornam incapazes de amar, de desenvolver a confiança no objeto.

Enfim, em lugar de simplesmente reduzir a discussão ao campo das estruturas, preferimos dar lugar a novos questionamentos sobre as organizações patológicas narcísicas de personalidade, em que estados narcísicos destrutivos estão a serviço da manutenção da identificação projetiva e, portanto, do superego arcaico, aspectos mutuamente relacionados aos laços sociais perversos. 
Há certamente esperança para aqueles que ainda podem navegar por águas menos turvas, ter acesso a um self libidinal e, neste lado saudável, ir em busca das boas relações objetais, sem se fechar em paradigmas tipológicos ou classificatórios, ou de visões negativistas sobre a natureza humana. Já é hora de discutir questões dolorosas para a sociedade e enxergar que crianças e adolescentes podem escrever novas histórias. Novas visões dadas às suas narrativas, às suas existências, novas formas de contar suas histórias de vida podem ser escritas, por que não? Serão os laços sociais perversos impenetráveis? Penso que este tecido pode ser esgarçado pela esperança de novos tempos e de uma sociedade eticamente orientada para o bem comum.

\section{Referências}

Bonfim, E. M. (2004). O julgamento de um serial killer. São Paulo: Malheiros.

Douglas \& Olshaker (2002). Mentes criminosas e crimes assustadores. Rio de Janeiro: Ediouro.

Freud, S. (1990). Recordar, repetir e elaborar. In Edição Standard Brasileira das Obras Psicológicas Completas de Sigmund Freud (Vol. XII). Rio de Janeiro: Imago. (Trabalho original publicado em 1914).

Holanda, A. B. (2012). Dicionário Aurélio da Língua Portuguesa. São Paulo: Positivo.

Klein, M. (1991). Notas sobre alguns mecanismos esquizoides. In Inveja e gratidão e outros trabalhos. Rio de Janeiro: Imago. (Trabalho original publicado em 1946).

Klein, M. (1991). Sobre o desenvolvimento do funcionamento mental. In Inveja e gratidão e outros trabalhos. Rio de Janeiro: Imago. (Trabalho original publicado em 1958).

Klein, M. (1996). Princípios psicológicos da análise de crianças pequenas. In Amor, culpa e reparação e outros trabalhos. Rio de Janeiro: Imago. (Trabalho original publicado em 1926).

Klein, M. (1996). Uma contribuição à psicogênese dos estados maníaco-depressivo. In Amor, culpa e reparação e outros trabalhos. Rio de Janeiro: Imago. (Trabalho original publicado em 1935).

Monteiro, K. (2012). Assassinos seriais: uma abordagem psicanalítica sobre o superego arcaico e os efeitos da sideração. Tese de Doutorado em Psicologia Clínica, Pontifícia Universidade Católica de São Paulo, São Paulo.

Winnicott, D.W. (1985). Deprivacion and delinquency. London: Tavistock Publication Ltd.

\section{Resumos}

(Serial killers and the effects of utter consternation on the psyche and social bonds)

The processes that characterize the constitution of subjectivity of serial killers have a relationship with the role played by the archaic super-ego. When we analyze the interfaces of these types of psychic configurations with social bonds we see serial killers 


\section{ARTIGOS}

treated as icons of the post-modern culture, to the extent that they are idealized in the cinema, books and television series. They are also idolized by many for their ability to mesmerize, deceive and defraud others. These characteristics leads persons to support and approve perverse social bonds present in contemporary society.

Key words: Archaic super-ego, serial killers, admiration, social bonds

(Les assassins en série et les effets de la sidération dans le psychisme et lien social)

Les processus qui caractérisent la constitution de la subjectivité des assassins en série se rapportent au rôle que le Surmoi archä̈que joue chez eux. En analysant les interfaces entre ces types de configuration psychique et les liens sociaux, nous observons que ces assassins en série sont traités comme icônes de la culture postmoderne, étant donné qu'ils sont idéalisés dans les films, les livres et dans les séries TV. Ils sont d'ailleurs admirés par un nombre important de personnes dî̀ à leur intelligence, ainsi qu'à leur capacité d'envoûter et de leurrer leurs victimes, qualités qui sidèrent et pactisent avec les liens sociaux pervers de notre contemporanéité.

Mots clés: Assassins en série, lieux sociaux, sidération, surmoi archaïque

(Los asesinos en serie y los efectos del encantamiento en la psique y el lazo social)

Los procesos psíquicos que caracterizan la constitución de la subjetividad de los asesinos seriales se relacionan con el papel que en ellos tiene el Superyó arcaico. El análisis de las interfaces de estes tipos de configuraciones psíquicas con los lazos sociales muestra que las figuras de los asesinos en serie son tratadas como si fueran símbolos de la cultura pós-moderna; son idealizados en las películas, en los libros y series televisivas además de ser objetos de culto, por muchos, por su inteligencia, capacidad de encantamiento y habilidad para engañar, características que pactúan con los lazos sociales perversos observados en la contemporaneidad.

Palabras claves: Asesinos en serie, encantamiento, lazos sociales, superyó arcaico

(Serienmörder und die Auswirkungen der Perplexität in der Psyche und der sozialen Bindung)

Die Vorgänge, welche die Subjektivität der Serienmörder kennzeichnen stehen in Verbindung mit der Rolle, die das archaische Über-ich für sie spielt. Untersuchen wir die Überschneidungen dieser Art von psychischen Konfigurationen mit den sozialen Bindungen, dann ist festzustellen, dass die Serienmörder als Symbole der postmodernen Kultur behandelt werden. Sie werden in Filmen, Büchern und TV-Serien idealisiert und außerdem von vielen für ihre Fähigkeit zu bezaubern, für ihre Intelligenz und Anziehungskraft verehrt. Diese Verhalten verblüffen und gehen mit den perversen sozialen Bindungen einher, die heutzutage beobachtet werden.

Schlüsselwörter: Archaische Über-ich, Perverse sozialen Bindungen, Serienmörder Verzauberung 
Citação/Citation: Monteiro, K. M. S. L. (2014, setembro). Assassinos seriais e os efeitos da sideração no psiquismo e no laço social. Revista Latinoamericana de Psicopatologia Fundamental, 17(3-Suppl.), 738-748.

Editor do artigo/Editor: Prof. Dr. Manoel Tosta Berlinck

Recebido/Received: 15.3.2014/ 3.15.2014 Aceito/Accepted: 15.4.2014 / 4.15.2014

Copyright: (C) 2009 Associação Universitária de Pesquisa em Psicopatologia Fundamental/ University Association for Research in Fundamental Psychopathology. Este é um artigo de livre acesso, que permite uso irrestrito, distribuição e reprodução em qualquer meio, desde que o autor e a fonte sejam citados / This is an open-access article, which permits unrestricted use, distribution, and reproduction in any medium, provided the original author and source are credited.

Financiamento/Funding: A autora declara não ter sido financiada ou apoiada / The author have no support or funding to report.

Conflito de interesses/Conflict of interest: A autora declara que não há conflito de interesses / The author has no conflict of interest to declare.

\section{Klaylian Marcela Santos Lima Monteiro}

Doutora em Psicologia clínica pela Pontifícia Universidade Católica de São Paulo -PUC-SP; Professora e Coordenadora de período da FPS - Faculdade Pernambucana de Saúde (Recife, PE, Br); Psicóloga e supervisora de residentes e estagiários no IMIP - Instituto de Medicina Integral Prof. Fernando Figueira - Recife, PE

Av. Conselheiro Aguiar, 2738/605 - Boa Viagem

51020-020 Recife, PE, Br

e-mail: marcelamonteiro@globo.com 